\title{
IDENTIDAD CHILENA Y EL BICENTENARIO
}

\section{Jorge Larraín}

Este artículo explora la evolución de la identidad chilena durante los doscientos años de su existencia. Reconoce la existencia de algunos contenidos de larga duración y los analiza, pero al mismo tiempo sostiene la historicidad de los relatos, sentimientos y dimensiones que la conforman. Distingue cuatro hitos de su desarrollo en el tiempo: la independencia a principios del siglo XIX, el fin del estado oligárquico alrededor del primer centenario, el golpe militar de 1973 y la vuelta a la democracia en 1990. En cada una de estas fases se busca establecer lo que cambia y sus contenidos más distintivos. Se termina con un esfuerzo por discernir las características principales del relato identitario predominante hoy día y sus diferencias con la perspectiva del centenario.

Palabras clave: identidades nacionales; cultura; identidad chilena; bicentenario.

Recibido y aceptado: noviembre 2010.

Jorge Larraín. Doctor en Sociología, Universidad de Sussex, Inglaterra. Vicerrector Académico de la Universidad Alberto Hurtado. Autor de numerosos artículos académicos y libros, entre ellos Identidad Chilena (LOM, 2001). Su más reciente contribución es la serie de cuatro volúmenes sobre El Concepto de Ideología (LOM, 2007-2010). 


\section{Introducción}

$C_{\text {hile ha estado celebrando durante } 2010 \text { el bicentenario de la }}$ nación y con esta ocasión ha empezado a reflexionar sobre la identidad nacional y su estado actual. Al llegar a los dos siglos de vida independiente es obvio que tiene mucho interés evaluar el camino recorrido, de dónde se viene y cómo se ha cambiado, cuáles son los rasgos más estables y si se ha mantenido un rumbo discernible, qué ha dado resultado y qué ha fracasado. Las identidades nacionales, y por lo tanto la identidad chilena, no son inmutables, se construyen en el tiempo y van cambiando. Dar cuenta de esos cambios, reflexionar sobre lo que se ha hecho y sobre el curso actual que se sigue, sobre las aspiraciones y proyectos, es sin duda de primera importancia para un aniversario, más aún cuando los embates de la globalización hacen pensar a muchos que la identidad chilena está amenazada o desdibujándose bajo el impacto de otros valores y otras culturas.

Las identidades nacionales no son fenómenos simples y tienen varias dimensiones íntimamente unidas. Por un lado expresan un sentimiento de unidad, lealtad recíproca y fraternidad entre los miembros de la nación ${ }^{1}$. Por otro, se manifiestan en una pluralidad de discursos que construyen una narrativa acerca de la nación, su origen y su destino. En cada época, alguno de esos relatos predomina en el favor popular. Estos relatos se refieren no sólo a lo que somos o hemos sido, sino también a lo que queremos ser; no se constituyen solo en el pasado remoto, son también un proyecto de futuro. Como propone Habermas, "la identidad no es algo dado previamente, sino también, y de manera simultánea, nuestro propio proyecto" . Solo que al hablar de "nuestro propio proyecto", de ninguna manera ello puede concebirse como un único proyecto compartido por todos, sino que como una variedad de relatos o propuestas alternativas de futuro que buscan ganar el apoyo de la gente. Ningún proyecto de futuro articulado por un discurso específico podría pretender tener un monopolio de la construcción de la identidad sin antes tratar de convencer a la gente común, sin buscar entroncarse con las formas populares, las tradiciones y los significados sedimentados en la vida cotidiana de la gente por prácticas de mucho tiempo.

${ }^{1}$ Esta dimensión ha sido destacada por Benedict Anderson al concebir a la nación como una "comunidad imaginada" cuyos miembros sienten un grado de lealtad recíproca aunque no se conozcan. Véase Imagined Communities, 1983.

2 J. Habermas, "The Limits of Neo-Historicism”, 1992, p. 243. 
Esto es muy importante, primero porque descarta la idea mítica $\mathrm{y}$ un tanto ingenua de que en asuntos de identidad nacional hay una sola versión que nos une a todos. Segundo, porque en la construcción del futuro, no todas las tradiciones históricas y contenidos identitarios tienen el mismo valor. Habermas insiste en la profunda ambivalencia de las tradiciones nacionales: no todo lo que constituye una tradición nacional es necesariamente bueno y aceptable para el futuro. Quizás sea cierto que una nación no puede escoger libremente sus tradiciones, pero al menos políticamente puede decidir si continuar o no con algunas de ellas. El bicentenario es una buena ocasión, no solo para celebrar nuestra identidad, sino también para reflexionar críticamente sobre algunos aspectos de lo que hemos sido y el impacto que eso ha tenido, por ejemplo en las relaciones con nuestros vecinos. En este marco se inscribe la pregunta que surge con fuerza a propósito del bicentenario: ¿qué es lo que queremos ser? Y dentro de esa pregunta general se inscriben otras tales como, ¿es o debiera ser el desarrollo económico nuestra principal meta? Y suponiendo que lo fuera, en la búsqueda del desarrollo ¿le daremos prioridad a la igualdad o a la libertad?; ¿favoreceremos una fuerte intervención estatal o la total libertad de mercados?; ¿nos orientaremos a Estados Unidos, a Europa o hacia América Latina?; ¿buscaremos la integración regional o preferiremos mantener una cierta distancia con América Latina?, etc. Hay opciones que tomar y es bueno saber que no estamos predeterminados a seguir solo un curso de acción.

Otra dimensión importante de las identidades nacionales tiene que ver con su relación con la cultura nacional. Parece importante hacer una distinción entre cultura e identidad. La cultura es algo más general porque incluye todas las formas simbólicas y la estructura de significados incorporados en ellas. Todos los actos lingüísticos, acciones humanas y cosas materiales que se intercambian caben en ella ${ }^{3}$. La identidad es, en cambio, algo más particular, porque implica por un lado un relato que utiliza sólo algunos de esos significados presentes en las formas simbólicas mediante un proceso de selección y exclusión, y por otro, solo algunos sentimientos, especialmente de lealtad y fraternidad. La cultura nunca tiene la unidad, la cohesión y la estabilidad que tiene una identidad y sus componentes simbólicos son normalmente de orígenes

${ }^{3}$ Esta noción simbólica de cultura se origina en Clifford Geertz, The Interpretation of Cultures, 1973, p. 5 y ha sido retrabajada por J. Thompson, Ideology and Modern Culture, 1990, p. 132. 
muy variados. Incluye una gran variedad de sentimientos humanos y sus significados simbólicos, pero no acentúa necesariamente los sentimientos de fraternidad y lealtad.

Las culturas son sistemas relativamente abiertos compuestos por una gran cantidad de significados y formas simbólicas de fuentes diversas y permeables a nuevas formas simbólicas y significados que provienen de otras culturas, especialmente en la época de la globalización, donde los contactos se han intensificado fuertemente. La identidad moviliza y selecciona algunas formas simbólicas y sentimientos previamente cargados de sentido por la cultura para construir un discurso particular sobre el "sí mismo". La discursividad identitaria tiene mucha mayor estabilidad en el tiempo que un simple acto de habla, porque no es cualquier discurso; es un destilado narrativo de modos establecidos y sedimentados de vida que también implican emociones y sentimientos de adhesión. De allí que la cultura cambia más rápido que la identidad. Como lo ha sostenido Alejandro Grimson, "las fronteras de la cultura parecen más permeables que las fronteras de la identidad"4.

Así por ejemplo, formas musicales, arquitectónicas, televisivas, literarias y gastronómicas de las más variadas culturas entran hoy con relativa facilidad en otras. Lo que no significa necesariamente que afecten la identidad colectiva de esas sociedades, aunque es posible que a la larga en algún aspecto puedan hacerlo. Por ejemplo, el tango es en muchos sentidos una forma musical aceptada y valorada en toda América Latina. Es parte de nuestra cultura. Pero no forma parte del relato identitario chileno o peruano. El charango, en cambio, aunque puede haber sido originalmente un instrumento boliviano, Chile lo ha incorporado a su relato identitario hasta el punto que un presidente de Chile lo regala como signo de chilenidad al cantante Bono (lo que promueve un reclamo boliviano). Distinto es el caso de la celebración de Halloween que cada vez más penetra en Chile como un rasgo cultural adoptado por vastos segmentos de la población. Pero nadie diría que amenaza nuestra identidad o que está a punto de constituirse en un rasgo de nuestro relato identitario. El temor y la oposición a la globalización cultural están frecuentemente alentados por la confusión entre cultura e identidad.

Las identidades nacionales cambian históricamente y no tienen una versión única definitiva capaz de establecer exhaustivamente y

${ }^{4}$ Alejandro Grimson, “Las Fronteras de la Globalización”, 2002. 
para siempre lo que les es propio. Aparecen nuevos relatos identitarios predominantes, se modifican los sentimientos de fraternidad, cambian los contenidos, se conciben nuevos proyectos de futuro. No existen los rasgos identitarios esenciales que no cambian y subsisten eternamente a través de la historia, inalterados. Esto en dos sentidos. Por un lado las identidades nacionales no contienen rasgos de carácter psicológico con asiento definitivo en una "personalidad" o "tipo de carácter" ya formado e incambiable. Una nación no tiene rasgos psicológicos estables como si fuera una persona. Las identidades nacionales tienen contenidos que no constituyen una estructura psíquica colectiva que sería compartida por todos los miembros de la nación. En segundo lugar, tampoco puede decirse que rasgos religiosos o morales pueden constituir la esencia permanente de una identidad nacional. Es cierto, pueden tener una durabilidad larga, pero aun así, cambian. Toda identidad colectiva es un proceso histórico de construcción en la cual algunos de sus contenidos se van modificando, o adquiriendo nuevos sentidos para la gente. Más aún, aunque es cierto que las identidades son más estables y duraderas que la cultura, en el largo plazo también pueden incorporar elementos nuevos traídos desde otras culturas.

No obstante lo dicho, es posible identificar en determinados momentos históricos un conjunto de rasgos que al menos temporalmente parecen configurar los contenidos de una identidad. Como consecuencia de acontecimientos históricos, van dejando una impronta más o menos profunda en vastos sectores de la nación. Dentro de los muchos elementos que constituyen los contenidos de una identidad nacional en un determinado momento hay algunos que destacan por su mayor presencia o gravitación en el largo plazo. Tienen bastante estabilidad en el tiempo y de alguna manera han figurado con significaciones parecidas desde hace mucho tiempo. Son los rasgos de más larga duración y marcan predisposiciones, sentimientos, gustos y modos de hacer las cosas más estables. Otros son de más reciente aparición o su sentido ha ido cambiando y siendo reinterpretado en nuevos contextos históricos o sencillamente duran poco y desaparecen. Es posible tratar de identificar estos factores y explicar su origen histórico y su permanencia, siempre que nos abstengamos de transformarlos en esencias intocables e inamovibles. Todos ellos tienen orígenes históricos que pueden y deben ser identificados y también la posibilidad de perder vigencia si las circunstancias históricas cambian. Si quisiéramos establecer los hitos principales de la evolución 
de la identidad chilena en el tiempo, hay que distinguir cuatro momentos o etapas claves: la independencia a principios del siglo XIX, el fin del estado oligárquico alrededor del primer centenario, el golpe militar de 1973 y la vuelta a la democracia en 1990.

\section{EI legado colonial}

Antes de revisar estos cuatro momentos claves para la identidad chilena es necesario establecer qué traíamos ya como futura nación al momento de la independencia. No es posible hablar de identidad chilena sin mencionar el importante legado de la colonia, de la cual surgen varios de nuestros rasgos identitarios de larga duración. Claudio Véliz ha sostenido, con buenas razones, que en América Latina se dan cuatro ausencias históricas claves que condicionan los orígenes de nuestra modernización y que marcan diferencias sustanciales con la modernidad europea: la ausencia de feudalismo, la ausencia de disidencia religiosa, la ausencia de una revolución industrial, la ausencia de algo parecido a la Revolución Francesa ${ }^{5}$. Si esto se pone en términos positivos, es decir, en términos de lo que realmente existió, se podría decir que, primero, hubo centralismo político no desafiado por poderes locales; segundo, un monopolio religioso católico no amenazado por denominaciones protestantes ni por movimientos religiosos populares; tercero, una orientación económica exportadora de materias primas y, por último, un poder político autoritario.

Estos rasgos fijan los contornos culturales de la identidad chilena. Se trata de una síntesis identitaria en la que priman las orientaciones de la vida rural, el apego a la tierra y una profunda religiosidad. Estos contenidos están acompañados por formas autoritarias de gobierno y modos de producción serviles. La mentalidad dominante es intolerante y sospecha de la modernidad científica ilustrada, tiene una actitud racista frente a los indígenas, desprecia el trabajo manual y está permeada de machismo. La Iglesia católica, indistinguible del poder político, impone la religión a los indios por la fuerza. La conquista de América por los españoles es acompañada por una Cristiandad que ha perdido la práctica de crecer inculturándose desde abajo y más bien ha destacado la lucha armada contra otras religiones (precisamente en 1492 España expulsa a

\footnotetext{
${ }^{5}$ Claudio Véliz, La Tradición Centralista de América Latina, 1984, pp. 15-16.
} 
judíos y moros de su territorio). Una de las consecuencias de esto, sobre todo en el siglo XVI, fue la imposición de la religión del imperio a todos los habitantes del nuevo mundo. De hecho es el Papa el que concede al rey español el derecho a las nuevas tierras, autoridad sobre los nuevos súbditos y la obligación de cristianizarlos. Casi inevitablemente, la evangelización se transforma en un factor de legitimación de la conquista y, en muchos casos, de la violencia que ella implica.

Es importante preguntarse si en la conquista de América la fe cristiana se expande mediante la fuerza, porque en la mentalidad de la época la empresa religiosa y la política no podían separarse. Salta a la vista la diferencia con la inculturación del evangelio en el mundo grecoromano: en América Latina no pareciera ser tan fácil afirmar que existió una inculturación cristiana desde abajo en las culturas locales sino más bien, lo que terminó pasando fue la destrucción y el sometimiento de las culturas indígenas. Aunque varios sacerdotes y obispos se transformaron en defensores de los indios (Bartolomé de las Casas, Antonio de Montesinos) y reconocieron la presencia de Dios en esas culturas, los conquistadores cristianos y muchos eclesiásticos las despreciaron. En gran medida la Iglesia oficial se situó al lado del poder conquistador y aceptó la desigualdad básica entre los seres humanos y entre las culturas.

El tema de la evangelización tiene que entenderse en un primer momento directamente en relación con las culturas indígenas y no solo en relación con la nueva síntesis cultural que emerge de la conquista. Morandé pone el acento sobre esta última, argumentando que para la nueva síntesis cultural que se crea en Latinoamérica el rol de la Iglesia y de su evangelización ha sido clave, por su presencia orgánica en toda la región y por su capacidad de mediación. Para él la existencia de la dominación no es obstáculo para la constitución de esta nueva síntesis. Aunque el encuentro entre las dos culturas haya sido asimétrico, terminó por redefinir culturalmente a todos los implicados ${ }^{6}$. Estoy de acuerdo con esto, pero el énfasis sobre la nueva síntesis no debe impedirnos mirar críticamente el tipo de evangelización que existió con respecto a las comunidades indígenas y analizar hasta qué punto el evangelio se predicó a partir de sus propias categorías culturales.

${ }^{6}$ P. Morandé, Cultura y Modernización en América Latina, 1984, p. 148: “toda síntesis cultural nueva se produce en un contexto específico de dominación". 
Cuando se destacan las relaciones de mutua pertenencia y la intencionalidad de comprensión recíproca entre indígenas y españoles se hace en función de la nueva síntesis cultural que surge y que necesariamente tiene elementos comunes o compartidos. Pero esto no debe ocultar las consecuencias de una evangelización llevada a cabo bajo el amparo y con la ayuda del poder militar. Aunque haya continuidades "en el plano del ritual religioso, de la legitimación cúltica del trabajo y de la dilapidación festiva de los recursos económicos" ", esto no le quita el carácter de "impuesta" a la nueva religión, no impide el desarraigo forzado de las creencias anteriores y esto plantea preguntas muy importantes sobre el sentido mismo de la evangelización y las características de la religiosidad que emerge de allí y que juega un rol central en la síntesis identitaria colonial.

\section{Rasgos identitarios de larga duración}

De aquí surgen algunos rasgos de larga duración de nuestra identidad. Algunos son negativos, otros - frecuentemente la otra cara de los mismos rasgos negativos - son positivos. En este sentido muchos de estos rasgos están íntimamente relacionados. Es importante insistir en esta mezcla de rasgos positivos y negativos porque es improbable que ninguna identidad nacional consista solo en rasgos negativos. Sin embargo, en Chile y Latinoamérica ha existido la tendencia a exagerarlos como consecuencia de las opiniones europeas (nuestros "otros" significativos) que por siglos han recalcado nuestra supuesta inferioridad.

Un primer rasgo de larga duración combina centralismo y autoritarismo. El centralismo en Chile tiene poco que ver con los procesos modernizadores europeos asociados a la industrialización, el nacionalismo y las luchas políticas por la igualdad ${ }^{8}$. Se trata más bien de un tipo de centralismo que se consolida antes de la independencia y la industrialización sobre la base de una burocracia legalista y autoritaria impuesta por los reyes españoles. Este centralismo incluía poderes religiosos muy amplios que llegaban hasta la facultad de nombrar obispos y autorizar la construcción de iglesias y los viajes de todos los religiosos a América Latina. En Chile se acentúa más aun que en otros países

\footnotetext{
${ }^{7}$ P. Morandé, Cultura y Modernización en América Latina, 1984, p. 149.

${ }^{8}$ Véase Claudio Véliz, La Tradición Centralista de América Latina, 1984, p. 19.
} 
de América Latina debido a nuestras peculiaridades geográficas: se trata de un país largo y estrecho, con una gran variedad de regiones, climas y paisajes. Esta diversidad y las dificultades de comunicación determinaron desde un comienzo una conciencia más aguda acerca del peligro de disgregación territorial y por ende reafirmaron un fuerte centralismo 9 .

El poder absoluto de los gobernantes, la subyugación servil de los indígenas, pero también el monopolio religioso y la Inquisición, que se utilizaron como medios de control político, son las bases en las que se sustenta el autoritarismo, esa valoración exacerbada del rol de la autoridad. Este rasgo se extiende además de la religión y la política a las relaciones familiares y empresariales donde se combina con rasgos machistas. La persistencia en el tiempo de este rasgo y la admiración que despierta se muestra en la insistencia por una parte importante de la historiografía chilena acerca de que el gobierno portaliano, fuerte y autoritario, ha sido fundamental en la formación del estado chileno ${ }^{10}$. El propio Portales sostenía que "la democracia, tan predicada por los soñadores, es un absurdo en países como los americanos, llenos de vicios y donde los ciudadanos carecen de toda virtud"; había que adoptar el sistema republicano, pero incluyendo "un gobierno fuerte, centralizado, cuyos hombres sean verdaderos modelos de virtud y patriotismo, y así enderezar a los ciudadanos por el camino del orden y de las virtudes ${ }^{11}$. Si bien ésta puede ser una idea más bien mítica alimentada por los admiradores de Portales, que en ocasiones ha servido para arrojar dudas sobre la conveniencia de mantener siempre una democracia plena y respetuosa de los derechos civiles, no puede negarse que para vastos sectores ha existido una unión entre autoritarismo y orden virtuoso.

De igual modo las debilidades de la democracia durante el siglo XIX y XX, los periódicos derrocamientos de presidentes constitucionales mediante intervenciones militares llevaron a numerosas recaídas en el autoritarismo político. La enorme valoración del papel central de la autoridad hace que la acusación más dañina que puede hacérsele a un gobernante en Chile es la de no ejercer su autoridad. Es también notorio

${ }^{9}$ Véase sobre esto Hernán Godoy, El Carácter Chileno, 1976, capítulo III.

${ }^{10}$ Véase por ejemplo A. Edwards, La Fronda Aristocrática en Chile, 1987, y M. Góngora, Ensayo Histórico sobre la Noción de Estado en Chile en los Siglos XIX y XX, 1981.

${ }^{11}$ Diego Portales, Carta a José M. Cea, marzo de 1822, en L. Zea, Fuentes de la Cultura Latinoamericana, 1993, tomo 2, p. 175. 
que aun el funcionamiento normal de la democracia en Chile favorece muy fuertemente el poder unipersonal del ejecutivo. Incluso nuestras dictaduras en el pasado han demostrado, sorprendentemente, un afán por actuar con arreglo a normas jurídicas, de aparecer respetando la ley y la constitución (aunque en lo fundamental las estaban violando).

Puede sugerirse como una hipótesis que el autoritarismo en Chile está de algún modo relacionado con la búsqueda del orden en la sociedad. En esto puede haber influido una geografía que hace más difícil controlar las regiones alejadas y muchos años de guerras permanentes con los mapuche durante la colonia. En situaciones de emergencia la relación autoridad-orden se hace más necesaria. De allí puede haber surgido la idea de una autoridad fuerte y virtuosa que asegure el progreso e impida el desorden, la arbitrariedad y la disgregación. Por otro lado, también es cierto que si bien Chile ha recaído periódicamente en gobiernos autoritarios durante los siglos XIX y XX, comparado con otros países de América Latina ha tenido desde muy temprano una historia de relativa mayor estabilidad política y respeto a la ley. Nuestro período de anarquía después de la independencia duró menos que en otros países.

Un segundo rasgo de larga duración conectado con el anterior se muestra en la simulación y el legalismo hipócrita del "se acata pero no se cumple". Para salvar la vida muchos indios simularon convertirse al cristianismo, mientras para salvar sus ganancias muchos españoles simularon acatar las órdenes del rey de no maltratar a sus indios. El se "acata pero no se cumple" anuncia la voluntad de obedecer a pesar de que no existe la intención real de hacerlo. De este modo se mantiene el principio de autoridad, al menos en apariencia. Marcos García de la Huerta ha sugerido que muchas veces las violaciones prácticas de la norma fueron conocidas por la autoridad, pero intencionalmente ignoradas, porque sabían que exigir su cumplimiento tenía algunas desventajas $^{12}$. Un ejemplo típico de esto puede verse en los católicos chilenos que profesan públicamente su obediencia a las enseñanzas del Papa acerca de la contracepción, pero hacen uso de ella abrumadoramente, a menudo con la complicidad de sacerdotes y obispos, a quienes no les importa que el problema de personas individuales se resuelva violando un precepto, con la condición de que en público se siga manteniendo la norma.

12 Véase Marcos García de la Huerta, Reflexiones Americanas: Ensayos de Intra-Historia, 1999, p. 123. 
De manera más general, actualmente reconocemos este rasgo en nuestro excesivo legalismo, la adherencia formal y ritualista a la norma, que encubre una disposición a ignorarla en la práctica; y también en nuestra pasión por la cosmética, "el aparecer bien" para triunfar en la vida, el que "no se note pobreza". Las formas de ostentación en mansiones y vestimentas de la oligarquía en el siglo XIX, se prolongan hoy en la importancia desmedida de los expertos en "imagen" pública. Somos un país obsesionado por la imagen que proyectamos, nos importa en demasía cómo nos ven desde afuera. Si revisamos las reacciones de la prensa, comentaristas y políticos al exitoso rescate de los 33 mineros en Copiapó, se verá que uno de los principales motivos de regocijo es la imagen que hemos logrado proyectar internacionalmente. ¡Cuántas universidades chilenas salen en los medios con iniciativas y programas que no implican avances reales ni contribuciones a la investigación o al conocimiento, pero "visten" y dan la apariencia de seriedad académica!

Pero también el legalismo chileno, aunque exagerado hasta el punto de la hipocresía, tiene otra cara: de alguna manera indica un afán de respeto al orden jurídico, una voluntad de regirse por el imperio impersonal de la ley, por el deseo de vivir en un orden que respeta el derecho de cada cual. La misma simulación tiene todas las desventajas que se le atribuyen a la hipocresía, la falta de principios y el engaño, pero al mismo tiempo puede verse desde un ángulo diferente que tal vez Nietzsche habría destacado: la capacidad acrecentada de sobrevivencia, la destreza para arreglárselas en condiciones de gran precariedad, la astucia para sortear situaciones amenazantes para la vida, la habilidad de desarrollar toda clase de recursos para subsistir.

Parte de las destrezas empresariales, técnicas y de gestión que los sectores populares y más pobres desarrollan en Chile y América Latina y de la que hablan historiadores como Julio Pinto y Gabriel Salazar (por ejemplo la famosa técnica del "alambrito" para reparar cosas), está relacionada también con esta astucia espontánea para presentarse con algún disfraz, para torcer un poco la verdad, para usar lo que no está estrictamente indicado, con el fin de sacar adelante pequeños emprendimientos y negocios un poco al margen de la legalidad pero dentro de lo aceptable. Es lo que también se denomina "pillería", que nunca tiene el rango completo de fraude o mentira pero que lo bordea.

Una tercera característica de larga duración es una persistente religiosidad popular cúltica y ritual, de procesiones y actos masivos 
alejados de la cotidianidad y que no siempre tiene un correlato de conversión personal, de fe que guía la vida diaria. Muy posiblemente esto se debe a que la existencia de la dominación y la fuerza dificultan una aceptación voluntaria, por convencimiento (inculturación desde abajo) del evangelio. Independientemente de su rol en la formación de la identidad latinoamericana, el catolicismo que se formó pareciera tener dos rasgos importantes: primero, se trata de un catolicismo de rasgos acentuadamente cúlticos y rituales donde destacan las devociones a los santos, las procesiones, las representaciones dramáticas, los bailes, la música y el canto, los actos masivos (como bautismos multitudinarios), etc. Es lo que se ha denominado religiosidad barroca. En esto influyó también, sin duda, el Concilio de Trento y las luchas anti-protestantes de la Iglesia española. Segundo, frente a la imposición forzada de un catolicismo basado en una cultura ajena y más poderosa, surgen entre los indios las reacciones de simulación que terminan en un sincretismo popular soterrado que subsiste hasta hoy. La conversión personal es reemplazada por el cumplimiento formal de actos externos de carácter cúltico, que se funden con antiguas creencias y que permiten sobrevivir a los indios sin arriesgar un castigo. En este cuadro surge la pregunta acerca de si una verdadera conversión o inculturación del evangelio es posible en estas condiciones.

Tal vez sería exagerado proponer una tesis que negara el carácter de verdadera evangelización a todo lo que sucedió en el siglo XVI en América Latina. Es cierto que en los casos límites, en los que no se respetó para nada la libertad de los indios y se les forzó a bautizarse bajo apercibimiento de muerte o castigo físico - que fueron numerosos pero nunca la totalidad - se podría dudar de que haya existido una evangelización propiamente dicha. Pero hubo también otras formas intermedias que apelaron a la persuasión más que a la fuerza, por mucho que existiera un clima general de presión o intimidación que favoreciera la conversión. Por otro lado, el carácter acentuadamente cúltico del catolicismo que se predicaba, tampoco invalida necesariamente la evangelización. Es cierto que el énfasis en el culto externo puede favorecer el ocultamiento de una falta de convencimiento personal, pero por otro lado el catolicismo siempre tendrá necesariamente una parte ritual y cúltica en la medida que se dirige a seres humanos que necesitan manifestaciones concretas de su religiosidad. 
Sin embargo, también sería una exageración proponer la tesis contraria en el sentido de que la evangelización que existió no tuvo limitaciones o imperfecciones y se adaptó perfectamente al ethos cultural indígena. Una cosa es reconocer las características sociológicas y religiosas que tuvo el proceso de evangelización en América Latina y otra muy distinta es darle a ese proceso la categoría de paradigma o de ethos cultural fundamental que deberíamos aceptar sin problemas. Es legítimo preguntarse críticamente tanto sobre el carácter cúltico y masivo de la evangelización que se llevó a cabo, como sobre la confusión que existió entre los intereses del cristianismo y los del poder político. En otras palabras, la evangelización que existió durante la conquista debe ser juzgada no solo en función de la creación de un ethos cultural distinto, sino también en función del respeto a los indígenas y su cultura.

Aun así, esta religiosidad excesivamente ritualista y de ocasiones solemnes, que no permea la vida diaria, tiene como expresión comunitaria una extraordinaria persistencia en el tiempo y una fortaleza notable frente a la modernidad secularizante. Es menos una búsqueda de salvación individual y más una expresión colectiva, una catarsis comunitaria unida estrechamente a una fecha especial y a celebraciones y fiestas que exceden lo puramente religioso. Cierto, esta forma de expresión religiosa comunitaria puede ser precaria y ocasional, suele bordear la creencia mágica en la capacidad de intercesión o de concesión de favores que se le entrega a una virgen, santo o "animita" y por ello no implica necesariamente un verdadero cambio de vida, pero le da sentido a un grupo humano que cree profundamente en que hay que pagar cada favor concedido como un asunto de gratitud y justicia.

Otro rasgo de larga duración es el cortoplacismo y la imprevisión. Deriva de una concepción del tiempo muy internalizada: el tiempo es corto y hay que aprovechar el momento. Realmente no existe o no se puede confiar en el futuro, que es siempre incierto y amenazante. Parafraseando una expresión de nuestra época, en el largo plazo estamos todos muertos. En parte esto está relacionado con una inseguridad vital muy fuerte determinada por una naturaleza difícil, por la pobreza y por la violencia de la conquista que sufrieron los indios. Pero en parte también ya existía en las culturas indígenas antes de la conquista: la historia se consideraba como destino y catástrofe ineludible, no como progreso. También entre ellas existía la conquista, la dominación y el sufrimiento de los vencidos. El largo plazo no existe en cuanto tiempo abierto a 
cambios positivos. Todo está determinado desde el pasado y con una carga negativa. No existe un tiempo lineal en el que puedan surgir situaciones nuevas, el futuro está gobernado por el pasado, por lo que ya ocurrió, y que se repite.

Esta actitud se nota ya en la concepción religiosa de la vida que tenían los indígenas: el trabajo es sufrimiento, no se hace para ahorrar y construir el futuro, se hace "para poder realizar la celebración ritual; se produce para que haya ofrendas disponibles a la consagración religiosa"13. Extrapolando esto se podría decir que se trabaja el mínimo para después pasarlo bien, no tanto para acumular. De allí las consideraciones de Morandé sobre la fiesta y el sentido del desperdicio ritual: después del trabajo duro hay que echar la casa por la ventana y nada importa el futuro. Por eso frecuentemente se acompaña con la expresión "lo comido y lo bailado no me lo quita nadie". Esta tendencia continúa hoy apoyada por las enormes diferencias sociales y de riqueza entre ricos y pobres. La mayoría no tiene certezas, no sabe si conservará su trabajo en el futuro, si podrá educar bien a sus hijos, si tendrá salud. La mayoría de los chilenos vive en una inseguridad total con respecto al futuro y frente a ello desarrollan un cierto fatalismo. El negocio de algunos "brokers" en Chile ha sido persuadir a gente común que se jubilen por adelantado aunque pierdan una pensión digna para el futuro. La gente está dispuesta a oírlos y a solucionar su problema inmediato, pero terminan con pensiones miserables porque no previeron las necesidades del futuro.

Todavía es posible encontrar esta misma inclinación en la actitud de algunos empresarios chilenos. Su objetivo es también aprovechar el momento, hacer ganancias grandes y rápidas para después vivir de las rentas: no tienen el sentido de la acumulación moderada pero constante de largo plazo. Un buen número de empresarios triunfadores en Chile son todavía especuladores, son los que lograron darle "el palo al gato", rápido, en un golpe de suerte o habilidad, aprovechando circunstancias favorables. También políticas de gobierno son a veces de corto plazo: las ventajas inmediatas impiden ver las desventajas de largo plazo.

Existe también un lado más positivo del cortoplacismo y la imprevisión. Consiste en una mayor intensidad de vida, un saber aprovechar el momento, una capacidad de gozar con las cosas chicas que vie-

${ }^{13}$ Pedro Morandé, Cultura y Modernización en América Latina, p. 90. 
ne dado precisamente por ese sentimiento de lo efímero que es todo. La imprevisión y la falta de planificación del futuro contribuyen también a una cierta frescura o mayor espontaneidad de las reacciones que no siempre se "calculan" pensando en lo que le dará a uno mejores réditos o beneficios de largo plazo. La espontaneidad permite reacciones más desinteresadas en las que la compasión o la solidaridad se sobreponen al cálculo egoísta del "como resguardar mis intereses en todo lo que hago".

\section{Cambios identitarios en cuatro momentos claves: la independencia}

Con el proceso de independencia alcanzó un punto culminante una crisis de identidad que había estado desarrollándose en Chile desde finales del siglo XVIII. Los criollos locales habían ido adquiriendo cada vez más conciencia de sí como grupo, y su identidad diferente se manifestaba en muchas luchas por el reconocimiento. Las elites locales hacían muchas peticiones y presentaban variadas quejas, lo que indicaba su cohesión cada vez mayor y una clara conciencia de sus intereses. Como ha mostrado Jocelyn-Holt en el caso de Chile, esta creciente auto-conciencia se manifestaba no solo como cohesión de clase, sino también como identidad regional o local, como un sentido de 1o "chileno"14. No obstante, después de la independencia el sentido de chilenidad era mucho más precario de lo que es hoy: se estaba saliendo de una crisis de identidad, una transición entre ser colonia española y ser país independiente, mediada por una guerra con chilenos en ambos bandos. Además, el componente latinoamericano de la identidad chilena era mucho más relevante de lo que es hoy. Las identidades nacionales no habían terminado por perfilarse bien y los intereses comunes y la colaboración entre los líderes de las distintas regiones para lograr la independencia pesaba más que los intereses locales de cada país.

El Estado jugó un rol importante en la creación de los símbolos, ritos y celebraciones que expresan la identidad nacional; pero en un comienzo la idea de pertenecer a una misma patria en que todos participan por igual es todavía muy débil; el sentido de fraternidad entre los chilenos es escaso por las divisiones naturales de la guerra y también por las profundas desigualdades y exclusiones de una sociedad elitista. En

${ }^{14}$ Alfredo Jocelyn-Holt, La Independencia de Chile, 1992, p. 120. 
contraposición con la colonia, el discurso identitario predominante en el siglo XIX proponía "orden y progreso" y deshacerse de una identidad colonial autoritaria, racista e intolerante. Buscaba construir la nueva identidad con los valores ilustrados de libertad política y religiosa, tolerancia, ciencia y razón. Su influencia condujo a las nuevas repúblicas a eliminar la esclavitud, a establecer formas democráticas y republicanas de gobierno y la libertad educacional y religiosa.

Pero, desde un comienzo se creó una distancia importante entre los principios liberales proclamados y la realidad de exclusión y explotación semiservil de las mayorías campesinas. Se adoptaron muchos valores de la Ilustración sólo en teoría y el progreso de la democracia se restringió a las clases dominantes. Como ha afirmado Hale, se aplicaron ideas liberales en un medio ambiente que era "resistente y hostil" "en países que estaban sumamente estratificados, social y racialmente, subdesarrollados económicamente y en los que estaba arraigada profundamente la tradición de una autoridad estatal centralizada"15. El nuevo discurso identitario era pro europeo. Chile tenía que ser civilizado y erradicarse sus rasgos culturales atrasados y bárbaros bajo la influencia europea. No debe sorprender entonces que algunas de las políticas que se sugerían para modernizar a Chile consistían en mejorar su raza mediante la inmigración europea o en una imitación un poco servil de concepciones, instituciones y modelos educativos y políticos europeos.

Aunque según Encina es en el campo de batalla de Yungay donde surge por primera vez desde la independencia un vínculo que une a todos los chilenos, es decir, surge el "sentimiento de la nacionalidad"16, es más bien la guerra del Pacífico la que termina por consolidar un sentido más fuerte de pertenencia y comunidad, especialmente después del combate naval de Iquique que aunó voluntades y galvanizó a Chile entero produciendo una ola de patriotismo. No es sorprendente que después de esta guerra florezca en la pluma de Nicolás Palacios ${ }^{17}$ un relato militar y racial de la identidad chilena, que ensalza nuestras virtudes bélicas. Esta versión de identidad le concede un lugar central al ejército, a la guerra y a las virtudes bélicas de la raza en la identidad chilena. Busca rescatar al "roto chileno" como encarnación de esa chi-

${ }^{15}$ Charles A. Hale, "Political and Social Ideas in Latin America, 1870-1930", en L. Bethell (ed.), The Cambridge History of Latin America, 1986, tomo 4, p. 368.

${ }^{16}$ Francisco Antonio Encina, Historia de Chile, desde la Prehistoria hasta 1891, 1940-1952, Tomo 2, p. 495.

${ }^{17}$ Nicolás Palacios, Raza Chilena, 1904. 
lenidad, y lo define como una mezcla de araucano y godo, poseedor de una psicología patriarcal apta para la guerra. Pero este relato nunca fue plenamente dominante y fue perdiendo influencia hasta desaparecer durante el siglo XX.

\section{La crisis del estado oligárquico para el centenario}

La revolución de 1891 y la crisis económica y social en la época del centenario introducen serias divisiones identitarias. Es la época en que comienza el derrumbe político del poder oligárquico que había controlado el Estado y la economía de Chile en el siglo XIX. Es una época de agitación política y huelgas violentas, de surgimiento del movimiento obrero y de las clases medias alimentados por la llamada "cuestión social" que se desata a partir de la crisis económica. Al producirse una seria polarización política las concepciones tradicionales de la identidad chilena son también cuestionadas. En los escritos de Recabarren y Huidobro, en los discursos de MacIver y los análisis de Venegas se cuestiona el rol político de la oligarquía, la falta de oportunidades, la pobreza, el desquiciamiento moral y las deficiencias de la educación. Es el momento en el cual aparece un discurso político de izquierda que trae un nuevo imaginario identitario, de igualdad, trabajo, industrialización y participación política de las clases medias y obreras auspiciadas desde el Estado y que, con altos y bajos y con algunos cambios, perdura durante el Frente Popular y alcanza hasta la Unidad Popular.

Las coaliciones populistas que asumen el poder buscaban el cambio político y la incorporación de las clases medias en la administración del Estado. Lograron el favor de las masas ampliando el sufragio, movilizando a las masas anteriormente excluidas ofreciéndoles nuevos empleos, formas del Estado de bienestar social y legislación social. Así se aseguró la estabilidad de los regímenes recién formados. Tanto las clases medias como las clases trabajadoras veían el Estado como el nivel determinante de la sociedad. Concebían el control del Estado como el único medio mediante el cual podrían redistribuir el poder económico y político en su favor. Durante esta etapa se crea un discurso identitario en el que priman rasgos anti-imperialistas y nacionalistas, una valorización del mestizaje y una creciente conciencia social sobre los problemas de la clase obrera. La línea gruesa del discurso es de apertura política, derechos sociales e industrialización. La nueva síntesis identitaria tenía, 
por lo tanto, una matriz igualitaria y desarrollista que combinaba una aspiración al desarrollo industrial con apoyo estatal y con ampliación de los derechos de los trabajadores.

\section{EI golpe militar de 1973}

Con la dictadura se entra en una etapa de crisis aguda, se reactualizan nuestros rasgos autoritarios y aparece una fractura interna en la identidad que todavía no sana del todo. Hay que reconocer que fuertes tensiones en la identidad nacional se habían ya producido con la llegada al poder de la Unidad Popular. Pero si bien el gobierno de Allende dividió al país políticamente y elevó los niveles de hostilidad y agresividad entre partidarios y adversarios, lo que dificultó un sentido de fraternidad compartida, el régimen militar pasó de la agresividad y hostilidad a la tortura y la eliminación física del "otro" derrotado, al que ya no se le consideró parte de la comunidad. La exclusión de la comunidad se extendió también de modo físico a los que se exilió, a los que no se dejó regresar, a los que no se les dio pasaporte y a los que se privó de la nacionalidad. Simbólicamente se extendió también a todos los que apoyaron (o se supone que apoyaron) al régimen anterior y permanecieron en el país: se les delató, se les vigiló, se les expulsó del trabajo, se les sometió a allanamientos masivos, se les denominó "humanoides" o "enemigos interno" o se les aconsejó que se fueran a Cuba.

Nada atenta más contra el sentimiento de lealtad propio de una identidad nacional que algunos ciudadanos dejen de ser reconocidos como parte de la comunidad, o su integridad física no sea respetada y sus derechos sean sistemáticamente desconocidos. Al colocarlos fuera de la comunidad, se les niega un sentido de mínima fraternidad. Esto condujo a un Chile dividido y traumatizado por las violaciones sistemáticas de los derechos humanos. De aquí surgen algunos rasgos identitarios de más corta duración con los cuales Chile vivió cerca de 30 años: el miedo y el menoscabo de símbolos de identidad para un sector importante de la población. El uso masivo y repetido de la canción nacional y de la estrofa que específicamente glorifica a las Fuerzas Armadas, las celebraciones demasiado frecuentes de héroes y aniversarios militares, el uso ubicuo de la bandera y el escudo nacional por parte del régimen militar produjo su progresiva identificación con la dictadura y, para un sector importante, perdieron en parte su capacidad simbólica de 
significar la unidad de todos los chilenos. Esta desafección con ciertos símbolos patrios alcanza también al estadio Nacional y al buque escuela Esmeralda por haber sido lugares de muerte y tortura.

Después del golpe vino el miedo, en muchos casos el verdadero terror de los partidarios de la Unidad Popular: el terror a morir, a ser torturado, a perder a sus seres queridos. Más importante aún es el miedo de la población al conflicto, a tener que volver a sufrir experiencias traumáticas. Durante muchos años los jueces tuvieron miedo a hacer justicia en casos de violaciones a los derechos humanos y aun los mismos agraviados han temido demandar a los culpables conocidos. Tan profundamente instalado estaba este temor, que sólo después de la detención de Pinochet en Londres en 1998, durante el segundo gobierno de la Concertación, empezaron a prosperar las primeras querellas contra los violadores de los derechos humanos. También se notó el miedo de muchos políticos a provocar una nueva intervención de los militares, lo que los llevó a auto-censurarse y, a muchos, a votar en contra del juicio político a Pinochet cuando éste asumió su puesto en el Senado. Recién alrededor del 2003 la autocensura y el temor a manifestarse dejan de inhibir a personas e instituciones como la televisión.

Pero también aparece ahora una nueva amenaza de fractura en la forma de una insurgencia mapuche de carácter autonomista que plantea un nuevo desafío a la identidad chilena. Crecientemente en sus luchas por recuperar sus tierras y por obtener un reconocimiento como pueblos originarios que fueron despojados y que buscan reparación, han ido perdiendo el sentido común de nacionalidad y comunidad con el resto de los chilenos. Se sienten despreciados y expoliados. Hay un creciente sentido de constituir una nación diferente a pesar de que un número considerable de descendientes directos se han asimilados perfectamente a la nación chilena.

Si consideramos los discursos identitarios que florecen durante los años de dictadura, vemos un intento por resucitar una versión militar de la identidad chilena y elevar al ejército a la condición de progenitor y garante de la chilenidad. Durante estos años, el régimen militar hizo un esfuerzo consciente por hacer renacer la versión militar de la identidad nacional que Palacios había desarrollado a principios del siglo XX. Esto aparece especialmente en los discursos públicos de sus funcionarios, en la Historia del Ejército de Chile del Estado Mayor General del Ejército $\mathrm{y}$ en otros textos escritos por militares. A este relato se contrapone un 
discurso de carácter religioso que critica la orientación al mercado y las violaciones a los derechos humanos y destaca el carácter católico de la cultura nacional. La versión religiosa de la identidad nacional ${ }^{18}$ destaca la idea de que nuestra identidad tiene un sustrato católico y que la razón instrumental propiciada por la modernidad ilustrada no forma parte de nuestra cultura. Insiste en que nuestra cultura sería barroca y se caracterizaría por tener un carácter oral más que escrito y por privilegiar el conocimiento o racionalidad sapiencial más que la razón científico-lógica. Concluye que la identidad católica no ha sido reconocida por las elites y que esa identidad encuentra su mejor expresión en la religiosidad popular. Este relato introduce la sospecha de que los procesos modernizadores han fracasado o van a fracasar precisamente porque no han respetado esa identidad. La modernidad aparece como algo externo, lo que viene de afuera, como algo que no tiene una raíz propia.

Estas versiones corresponden sin duda a la realidad política imperante durante la dictadura. Por una parte está el poder ilimitado de los militares en su intento por refundar la sociedad sobre bases diferentes y, por otra, la desarticulación de toda oposición política basada en partidos, sindicatos o movimientos sociales, lo que obligó a muchos a canalizar a través de la Iglesia católica un cierto nivel de oposición que fuera tolerado. En un tiempo en que el pensamiento socialista y de izquierda no tenía ninguna legitimidad ni posibilidad real en Chile, para muchos jóvenes la única forma posible y más segura de oposición política podía realizarse sólo desde el pensamiento religioso.

\section{La vuelta a la democracia en 1990}

Tanto el discurso militar como el religioso pierden rápidamente vigencia después de la vuelta a la democracia. Desde 1990 se empieza a consolidar más claramente el surgimiento de un nuevo discurso identitario chileno que ha ido ganando adeptos y está muy presente en los medios de comunicación hasta hoy. Se trata de un relato de carácter empresarial sobre la identidad chilena que combina cuatro elementos principales $^{19}$. Primero, se concibe Chile como país emprendedor, exitoso y

${ }^{18}$ Una exposición clara de esta versión se encuentra en P. Morandé, Cultura y Modernización en América Latina, 1984.

${ }^{19}$ Sigo aquí en parte algunas ideas de Bernardo Subercaseaux, Chile ¿Un País Moderno?, 1996. 
ganador donde destaca el empuje, el dinamismo, la ganancia y el consumo como los nuevos valores centrales de la sociedad chilena. Es un Chile que conquista mercados en el mundo, que invierte exitosamente en los países vecinos, que aventaja a sus vecinos. Así como se hablaba de los cuatro tigres asiáticos, en el Chile de los noventa se hablaba de ser el jaguar de América Latina.

Segundo, se piensa Chile como un país diferente, distinto al resto de América Latina, fuera del Tercer Mundo, con rasgos europeos, donde las cosas se hacen bien y hay poca corrupción. Se contrasta esto con las dificultades de los vecinos que se atribuyen al desorden político y las malas políticas económicas. La decisión de exhibir un iceberg en la Exposición Mundial de Sevilla en 1992, quería simbolizar un país "cool", exento de todo tropicalismo. Hasta 1973 Chile se consideraba inserto en un proyecto compartido con América Latina. Hoy Chile parece creer en su carácter excepcional dentro de América Latina y debido a sus políticas económicas muy distintas se excluye de participar plenamente en proyectos comunes como el Mercosur. Chile no sólo se siente más próximo a Europa y Estados Unidos, los tratados de libre comercio con ellos demuestran que de hecho ellos son sus socios verdaderos. La percepción de ser diferente persistentemente reiterada por la prensa y los políticos acarrea las acusaciones de arrogancia y respuestas no muy amistosas de nuestros vecinos. Algunos analistas internacionales incluso llegaron a hablar del creciente aislamiento de Chile en América Latina.

Tercero, la aspiración más sentida es el desarrollo, es llegar a pertenecer al grupo de los países desarrollados, lo que se cree es inminente, una pura cuestión de aplicar políticas adecuadas. Se sostiene que Chile ya ha dejado de pertenecer al Tercer Mundo y ha pasado a compartir destinos con una comunidad más selecta y pequeña dentro de los países periféricos: la de los países en vías de desarrollo más exitosos (los cuatro tigres asiáticos). Si en los años 60 Chile era una sociedad consciente de los obstáculos al desarrollo y sin muchas ilusiones sobre el entorno internacional, hoy día en el relato empresarial prima el voluntarismo y la pérdida de conciencia acerca de los límites que impone la globalización. Mientras en el período que va desde 1950 a 1973 había clara conciencia sobre la necesidad del desarrollo pero no necesariamente mucho optimismo sobre la posibilidad real de alcanzar la meta en el mediano plazo, en los noventa se expande una conciencia de que llegar a ser un 
país desarrollado es no sólo posible sino que Chile está relativamente cerca de ese objetivo. Más aún, los últimos tres gobiernos, incluido el actual, se han planteado fechas precisas para el logro del desarrollo. En esta visión el desarrollo ha dejado de ser un proceso permanente y se ha transformado en una meta que puede lograrse en una fecha precisa. Se desliza aquí no solo un fuerte voluntarismo sino además una reducción del desarrollo a un nivel de ingreso per cápita.

Cuarto, se plantea que Chile es un modelo para otros, especialmente para América Latina. Hay orgullo de que organismos internacionales y diversas instituciones y políticos del mundo desarrollado manifiesten a menudo que Chile ha hecho las cosas bien y que otros debieran seguirnos. No hay nada que fascine más que proyectar una imagen internacional de que "hacemos las cosas bien" y ser reconocidos por eso. Hay una verdadera obsesión por ser "potencia" (alimentaria, frutícola, vitivinícola, minera), o "plataforma" para empresas internacionales deseosas de entrar en América Latina. Aquí incide también ese rasgo de más larga duración que tiene que ver con la importancia de proyectar una buena imagen frente a los otros. Pero actualmente ha sido reforzado por una conciencia nueva del éxito económico, de ser desarrollados, organizados, de nivel internacional. Los periodistas están siempre buscando en forma ansiosa que extranjeros y visitantes confirmen nuestra calidad y superioridad, nuestra capacidad para constituirnos en ejemplo. El rescate de los 33 mineros en Copiapó ha desplegado en toda su magnitud este rasgo hasta el punto que surgen preguntas sobre si en la desbordante alegría nacional prima el haber salvado a los mineros o más bien el haber proyectado una imagen tan buena hacia afuera, el poder decir "do it the Chilean way".

En el contexto del predominio actual de este relato identitario y como parte de la reflexión sobre nuestra identidad en el bicentenario surge la pregunta por América Latina y más concretamente por el vecindario de Chile. Esto no sólo porque en principio parte importante de lo que Chile es y ha ido construyendo es, en sí mismo, latinoamericano, y se comparte con otros más allá de las fronteras, sino también porque una serie de desencuentros y problemas con los vecinos ha puesto esta pregunta sobre la mesa con más fuerza que nunca. Allí están, y solo a modo de ejemplo, los recortes del gas argentino, el no cumplimiento de contratos y acuerdos y las revelaciones del apoyo chileno a Inglaterra durante el conflicto de las Malvinas; el conflicto con Bolivia por las 
aguas del río Silala, la ofensiva internacional boliviana por una salida al mar, la cancelación de la exportación de gas boliviano por Chile y de la venta de todo gas a Chile; por último Perú descubre un nuevo problema de demarcación de la frontera marítima con Chile por el cual nos demanda en La Haya, y plantea reclamos airados por una venta de armas nuestras a Ecuador durante su conflicto con el Perú diez años atrás.

La frecuencia y extensión de los incidentes con los tres países limítrofes ha hecho surgir muchas preguntas. En Chile se habla de vivir en un barrio complicado. La disyuntiva es aislarse y protegerse, o, por el contrario, abrirse e integrarse. Se pone así en juego una dialéctica entre lo nacional y lo regional que incide directamente sobre los modos como Chile ve su destino, sea separado o integrado con sus vecinos. Surge la pregunta clave sobre qué rol quiere Chile que juegue su región, el lugar geográfico donde se ubica y con el que comparte una historia común, en su proyecto futuro. Ésta es una pregunta que, quiéralo o no, tiene que responder.

Los problemas que Chile ha tenido con sus vecinos en los últimos años, más la creciente afirmación de un discurso identitario exitista y excepcionalista hablarían de una dinámica o proyecto de separación y camino propio, pero por otra parte, y contrariamente a lo que podría pensarse, de los problemas enumerados, surge también la duda de si Chile podrá tener éxito sin la ayuda de sus vecinos. Lo que ha pasado con el gas tipifica esto: por algo Chile fue uno de los más activos impulsores del anillo energético que integraría al cono sur, desgraciadamente sin mucho éxito. Es claro que la nueva versión de la identidad nacional chilena representa un obstáculo para la integración regional. Pero es bueno recordar que se trata sólo de una versión, que por más que haya sido exitosa en la última década, no es necesariamente la última palabra. La pregunta es cuánto puede durar.

Hasta el momento no se ve un cambio posible en el corto plazo. Chile se proyecta en el bicentenario como una nación que se pretende excepcional y diferente al resto de América Latina, como una nación que intenta reforzar su identidad propia a costa de su identidad latinoamericana. Después de los traumáticos diecisiete años de dictadura, Chile ha sufrido profundas divisiones internas y no es sorprendente que muchos de sus mejores esfuerzos se dirijan a reconstituir su unidad resquebrajada por los antagonismos políticos exacerbados y las violaciones a los derechos humanos. Al mismo tiempo un gran acuerdo sobre 
una política económica de corte liberal parece unir a la mayoría de los sectores políticos. Así se entiende un poco esa autorreferencialidad que nos caracteriza ahora último, esas ansias por constituirnos en modelo, por llegar a la meta antes que los demás. Pero quizás la misma realidad de la economía mundial en algunos años más nos pueda indicar que sin integrarnos como lo hizo Europa el futuro de América Latina, y el nuestro en particular, puede no ser tan promisorio.

En la medida que el relato empresarial expresa no solo un discurso sino también el dinamismo real de la economía del país, ha ido acompañado de sentimientos de optimismo en la población, pero más en términos de progreso individual que como un proyecto de participación colectiva. La gente siente que va mejorando, que tiene más chances que las que tuvieron sus padres, pero es consciente de los altos costos. Por eso mismo se mezclan también sentimientos de desconfianza hacia otros y un malestar producto de la dura lucha por salir adelante en este nuevo tipo de competencia. Ha ido creciendo un cierto sentimiento de desazón e inquietud que algunos autores han llamado "el malestar de la cultura". Varios estudios encuentran que en medio del crecimiento económico y el consumo ampliado, muchos chilenos se sienten inseguros e infelices por niveles más altos de estrés en sus vidas, por el endeudamiento, por la congestión y polución de las ciudades, por la delincuencia crecien$t^{20}$. Chile se percibe como una sociedad cada vez más egoísta, más individualista, menos respetuosa de los demás, más agresiva y menos sana moralmente a pesar de reconocer por otro lado los avances económicos obtenidos.

Así nos encuentra el bicentenario, más optimistas e individualistas en nuestro proyecto de desarrollo futuro, pero con mayores dosis de estrés y con menos sentido de un proyecto de vida en común con otros. Muy distinto a la problemática del centenario donde reinaba el pesimismo y los análisis críticos pero existía la esperanza de que la acción mancomunada de movimientos sociales y el Estado lograría cambiar las cosas. En el bicentenario Chile no parece tener un proyecto de cambio radical, más bien la idea de continuar desarrollando y perfeccionando las virtualidades del modelo adoptado. En el centenario, por el contrario, estaba todo por cambiar y había conciencia de la necesidad de movilizarse políticamente para lograr esos cambios. En 1910 las mayorías

${ }^{20}$ Véase FLACSO, Encuesta sobre Representaciones de la Sociedad Chilena, 1995, y PNUD, Desarrollo Humano en Chile, 1998. 
habían empezado a adquirir una perspectiva de clase, de conflicto de intereses entre grandes grupos sociales. En el bicentenario la perspectiva de clase casi no existe o está muy debilitada: predominan los intereses de grupos sectoriales y de los individuos.

En 1910 empezaba a expandirse la idea de que la intervención del Estado en la economía era vital para el desarrollo. Llegamos al bicentenario con una situación donde la ideología dominante cuestiona el rol del Estado, aunque sigue haciendo uso de él sin remilgos. En el centenario la aspiración de grandes mayorías era lograr la organización sindical; el bicentenario nos sorprende con una organización sindical debilitada y con la apatía y desinterés de muchos trabajadores. Para el centenario Chile no se sentía excepcional ni único en América Latina; en 2010 Chile pretende ser modelo. En 1910 no existía prácticamente nada del Estado de bienestar, el 2010 nos encuentra con avances importantes en salud, educación y seguridad social que los trabajadores del centenario no habrían podido siquiera imaginar. Hace un siglo no existía prácticamente conciencia acerca de un maltrato histórico a los mapuche y hacía muy poco que las fuerzas armadas habían terminado por "pacificarlos"; hoy día el movimiento mapuche se ha radicalizado y los chilenos empiezan a darse cuenta de que hay un problema de larga data no resuelto que afecta negativamente la identidad nacional.

Independencia, centenario y bicentenario: tres momentos históricos relevantes que perfilan tres mundos sociales, políticos y económicos vastamente diferentes, pero un solo país que ha ido construyendo su identidad en la dialéctica de la continuidad y el cambio.

\section{BIBLIOGRAFÍA}

Anderson, B. (1983). Imagined Communities. Londres: Verso.

Edwards, A. (1987). La Fronda Aristocrática en Chile. Santiago: Editorial Universitaria.

Encina, F. A. (1940-1952). Historia de Chile, desde la Prehistoria hasta 1891. XX tomos. Santiago: Nascimento.

FLACSO (1995). Encuesta sobre Representaciones de la Sociedad Chilena. Santiago: FLACSO.

García de la Huerta, M. (1999). Reflexiones Americanas, Ensayos de Intra-Historia. Santiago: LOM Ediciones.

Geertz, C. (1973). The Interpretation of Cultures. New York: Basic Books.

Godoy, H. (1976). El Carácter Chileno. Santiago: Editorial Universitaria.

Góngora, M. (1981). Ensayo Histórico sobre la Noción de Estado en Chile en los Siglos $X I X y X X$. Santiago: Ediciones La Ciudad. 
Grimson A. (2002). "Las Fronteras de la Globalización". Boletín Chileno de Comunicación. Año 4, № 46, Universidad Diego Portales.

Habermas, J. (1992): “The Limits of Neo-Historicism”. Entrevista con J. M. Ferry. En J. Habermas, Autonomy and Solidarity. Londres: Verso.

Hale, C. A. (1986). "Political and Social Ideas in Latin America, 1870-1930". En L. Bethell (ed.), The Cambridge History of Latin America. Cambridge: Cambridge University Press.

Jocelyn-Holt, A. (1992). La Independencia de Chile. Madrid: Editorial Mapfre.

Morandé, P. (1984). Cultura y Modernización en América Latina. Cuadernos del Instituto de Sociología. Santiago: Universidad Católica de Chile.

Palacios, N. (1904). Raza Chilena. Valparaíso: Imprenta y Litografía Alemana.

Portales, D. (1993). Carta a José M. Cea, marzo de 1822. En L. Zea, Fuentes de la Cultura Latinoamericana. México: Fondo de Cultura Económica.

PNUD (1998). Desarrollo Humano en Chile. Santiago: PNUD.

Subercaseaux, B. (1996). Chile ¿Un País Moderno? Santiago: Grupo Editorial Zeta.

Thompson, J. (1990). Ideology and Modern Culture. Cambridge: Polity Press.

Véliz, C. (1984). La Tradición Centralista de América Latina. Barcelona: Ariel. 